\title{
Estimation of voltage unbalance at an AC traction substation with different train operational scenarios
}

\author{
Thanatchai Kulworawanichpong*, Nattapong Mingpruk, Tosaphol Ratniyomchai \\ School of Electrical Engineering, Institute of Engineering, Suranaree University of Technology, Nakhon Ratchasima, 30000, Thailand
}

\section{A R T I C L E I N F O \\ Article history: \\ Received: 30 April, 2017 \\ Accepted: 24 June, 2017 \\ Online: 16 July, 2017}

Keywords:

Voltage unbalance factor

AC electric railway

Cyclic permutation of phases

connection

\begin{abstract}
A B S T R A C T
This paper presents the modeling and simulation of the voltage unbalance in the power supply system of an AC electrified railway. The operating voltage at the traction substation is obtained by MATLAB/SIMULINK program and the voltage unbalance is evaluated by considering the voltage unbalance factor (VUF). Suvarnabhumi Airport Rail Link (ARL), in Bangkok, Thailand, is chosen to be a case study. The ARL is supplied by two single-phase traction transformers connected as a cyclic permutation of phases. According to the extension plan of the ARL, four service scenarios with different headways, auxiliary loads and total weights of the trains were simulated to study how the different scenarios influence the VUF at the three-phase side. It can be summarized that at the same headway, the VUF was increased when the train weight and auxiliary power load were increased. In case of different headways, the longer the headway, the more voltage unbalance. The extension plan of the ARL in the near future can be achieved with the voltage unbalance level under the maximum allowable value.
\end{abstract}

\section{Introduction}

This paper is an extension of work originally presented in IEEE/SICE International Symposium on System Integration (2016) [1]. However, the additional experimental pieces proposed in this paper is that the voltage unbalance at an AC traction substation is effected by the three factors of the train operation, including train headway, number of train and additional auxiliary power. This consideration is evaluated for the extension plan of the ARL in the near future. The results would be verified and discussed as follows:

There are presently various forms of ground transportation that help the passengers, particularly the international tourists, to make a decision. The mass rapid transit system is one of the most favorite ground transportation systems and currently vital to developing countries, especially regarding the fundamental economy and society. In Thailand, the tourism industry grows quickly. Therefore, the number of the international tourists at the Suvarnabhumi airport also increased. The cheapest cost and shortest time to travel from the Suvarnabhumi airport to Bangkok city center and other mass rapid transit lines is traveling by the Suvarnabhumi airport rail link (ARL).

${ }^{*}$ Corresponding Author: Thanatchai Kulworawanichpong, 111 University Avenue Muang, Nakhon Ratchasima 30000 Thailand | Email: thanatchai@gmail.com
The power feeding system of the ARL is the $25 \mathrm{kVrms}$ overhead catenary system receiving electric power from the threephase AC transmission system. The traction substation transformers are connected as a cyclic permutation of phases, i.e. an alternate phase connection such as A-B, B-C, and C-A. In practical, the voltage unbalance and voltage drop are frequently occurred at the point of common coupling depending on the train operations. In additions, the State Railway of Thailand has planned to extend the service from Suvarnabhumi airport to Don Muang airport in the near future. Therefore, the energy consumption by trains at the traction substation will definitely increase. Obviously, the voltage unbalance at the three-phase side of the traction substation is likely to increase too. To assess the feasibility of the extension plan, four expected train operational scenarios have been simulated by using MATLAB/SIMULINK to evaluate the voltage unbalance and to study the effects of the headways, train weight, and auxiliary power on the voltage unbalance.

This paper presents the study of the voltage unbalance at the traction substation of the ARL in four different scenarios. The contents are divided into six sections. Section 1 is an introduction. Section 2 describes a train movement, power consumption, and voltage unbalance factor (VUF) calculation. Section 3 describes the ARL power supply system and parameters calculation. Section 4 presents the modelling in MATAB/SIMULINK and simulation 
procedure. Simulation results and discussion are described in section 5. Lastly, a conclusion is in section 6.

\section{Train Movement and Voltage Unbalance Calculation}

A train motion is calculated by the Newton's second law of motion taking account of gradients, speed limitation, modes of operation, etc. In order to obtain the required power, speed, and position of the train, it is indispensable to simulate a train movement. In this section, the basic modules within the train simulation are briefly reviewed [1]. In addition, the definition of the voltage unbalance factor is proposed.

\subsection{Train movement calculation}

A train motion is resisted by several resistive forces, e.g. train resistance, track gradient force, etc. The free body diagram of all forces acted upon the train on an inclined plane is shown in Figure 1. By applying Newton's second law, the train movement equation is expressed in (1):

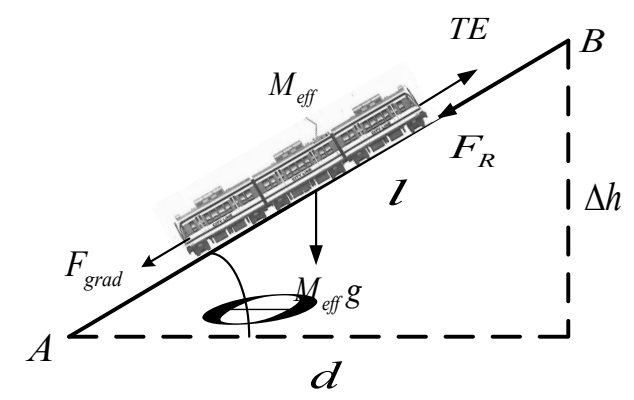

Figure 1. Free body diagram of a train on an inclined plane [1].

$$
F=T E-F_{\text {grad }}-F_{R}=M_{e f f} \alpha
$$

where $T E$ denotes the tractive effort $(\mathrm{N}), F_{\text {grad }}$ denotes the gradient force $(\mathrm{N}), F_{R}$ denotes the train resistive force $(\mathrm{N}), M_{\text {eff }}$ denotes the effective mass $(\mathrm{kg})$ and $\alpha$ denotes the train acceleration $\left(\mathrm{m} / \mathrm{s}^{2}\right)$

- Tractive effort (TE): the force generated by a locomotive to pull a train [2].

- Gradient force $\left(\mathrm{F}_{\text {grad }}\right)$ : the weight of a train opposes the train movement when a train is on a positive slope and helps accelerate when it is on a negative slope. The gradient force is usually expressed in the form of $\Delta h / l$, where $\Delta h$ is the vertical distance, 1 is the slope length or horizontal distance from point A to B, see Figure 1. With a small arbitrary angle $\theta$ the gradient force can be approximated by using (2), where $\mathrm{g}$ is the acceleration rate due to gravity of the earth.

$$
F_{\text {grad }}=M_{e f f} g \sin \theta=\frac{M_{e f f} g \Delta h}{l}
$$

- Train resistive force $\left(\mathrm{F}_{\mathrm{R}}\right)$ : the motion of the train is opposed by a number of resistive forces. The overall resistance can be formulated as follows [3]:

$$
F_{R}=A+B v+C v^{2}
$$

where $v$ is the vehicle speed $(\mathrm{km} / \mathrm{h})$ and the coefficients $A$ $(\mathrm{kN}), B(\mathrm{kNh} / \mathrm{km})$ and $C\left(\mathrm{kNh}^{2} / \mathrm{km}^{2}\right)$ are all constants called the Davis coefficients [4].

- Effective mass ( $\left.\mathrm{M}_{\mathrm{eff}}\right)$ : it is the sum of tare mass (mass of train without loads or passengers) and rotational inertia of the rotating components on the train which is expressed as follows [3]:

$$
M_{\text {eff }}=M_{t}\left(1+\lambda_{w}\right)+M_{l}
$$

where $M_{t}$ is the tare mass, $\lambda_{w}$ is the rotary allowance and $M_{l}$ is the freight or passenger load.

The modes of train motion considered in this study include accelerating, constant speed, coasting, and braking modes. The speed-distance curve describing each mode of motion is illustrated in Figure 2.

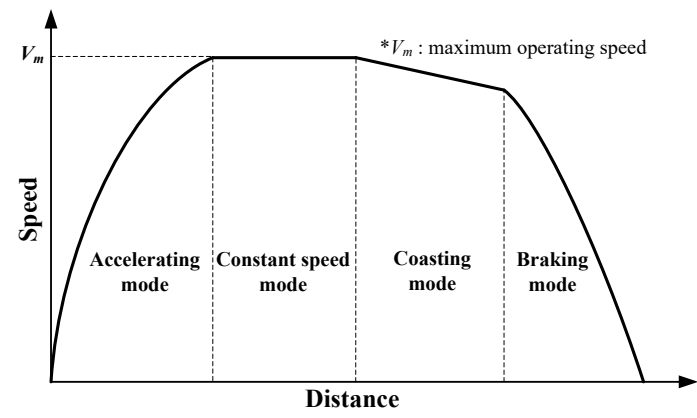

Figure 2. Train operating modes [1].

\subsection{Train Power Consumption}

The power required by a train $P$ is given by the following expression [5]:

$$
P=\frac{T E \times v}{\eta}+P_{a u x}
$$

where $\eta$ denotes the efficiency of conversion of the electrical power to the mechanical power, $T E$ denotes the tractive effort, $v$ denotes the instantaneous speed and $P_{a u x}$ denotes auxiliary power.

\subsection{Voltage Unbalance Factor}

The voltages of a three-phase power supply are ideally equal in magnitudes and phase angles of $120^{\circ}$ apart from each other. The three-phase system with those conditions are called a balanced three-phase system and its phasor diagram is shown in Figure 3A. If the three-phase voltage unbalance occurs, both magnitudes and phases are altered, see Figure 3-B. It can be seen that the neutral point $(n)$ will move to the position of $n_{2}$. The effects of voltage unbalance, for example, are: the reduction of three-phase induction motor operating lifetime, performance or even failure, etc.

According to IEEE 1159 - 2009, unbalance in a three-phase system is defined as the ratio of the magnitude of the negative sequence component to the magnitude of the positive sequence component, expressed as a percentage. This definition can be applied for either voltage or current. Typically, the voltage 
unbalance of a three-phase service is less than $2 \%$, especially when a single-phase load is presented. Mathematically, the voltage imbalance is represented as follows [7]:

$$
\% V U F=\frac{\left|V_{n e g}\right|}{\left|V_{p o s}\right|} \times 100 \%
$$

where $\% V U F$ is the percentage of the voltage unbalance factor, $V_{p o s}$ is the positive sequence component and $V_{\text {neg }}$ is the negative sequence component.

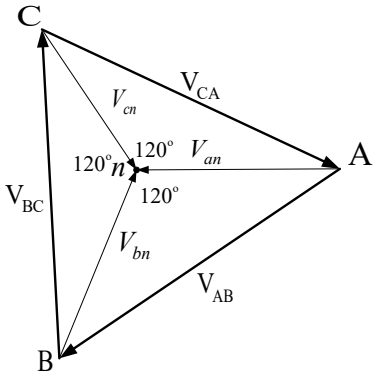

A

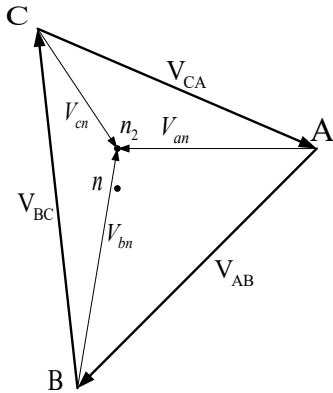

B
Figure 3. A) Phasor diagram of a three-phase voltage balance and B) Phasor diagram of a three-phase voltage unbalance (modified from [6]).

\section{ARL System Description and Parameters Calculation}

To obtain the voltage solutions of the three-phase power supply and the voltage unbalance factor at the point of common coupling of the ARL traction substation .The parameters calculation and structure of an AC traction power supply, a transformer connection, and an overhead contact system are briefly proposed as follows:

\subsection{Cyclic permutation of phases connection}

The connection by cyclic connection of phases as shown in Figure 4 can be considered for the advantages in disposition and easier operation of substations, whereas the three-phase shortcircuit power in the primary network is remarkably high if compared with single-phase load power. In this arrangement, the single transformer is fed with two phases and the primary threephase network can be balanced by systematically distributing the phase connection based on the traction loads [8].

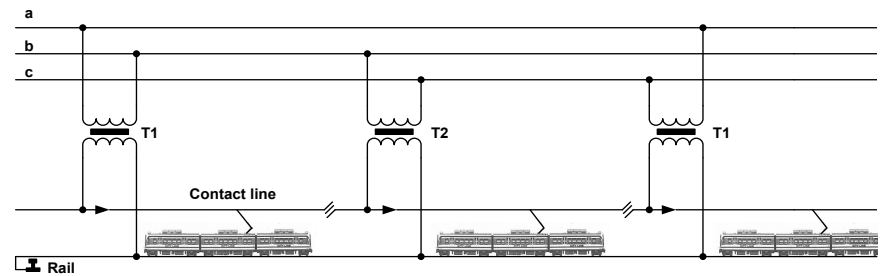

Figure 4. AC traction substation with cyclic permutation of phase

\subsection{Structure of the ARL Traction Power Supply}

The entire line of the ARL is supplied by a traction power substation (TPS) with $2 \times 20$ MVA transformers, located at 8.078 $\mathrm{km}$ near Ramkham Haeng station. A minimum short circuit capacity of the utility grid is 2.7 GVA. Transformer's characteristics data are: $\mathrm{Ur}=69 / 27.5 \mathrm{kV}, \mathrm{Sr}=20 \mathrm{MVA}$, Oil Natural Air Natural, Ukr. $=12 \%$. The single-line diagram of the substation is illustrated in Figure 5.

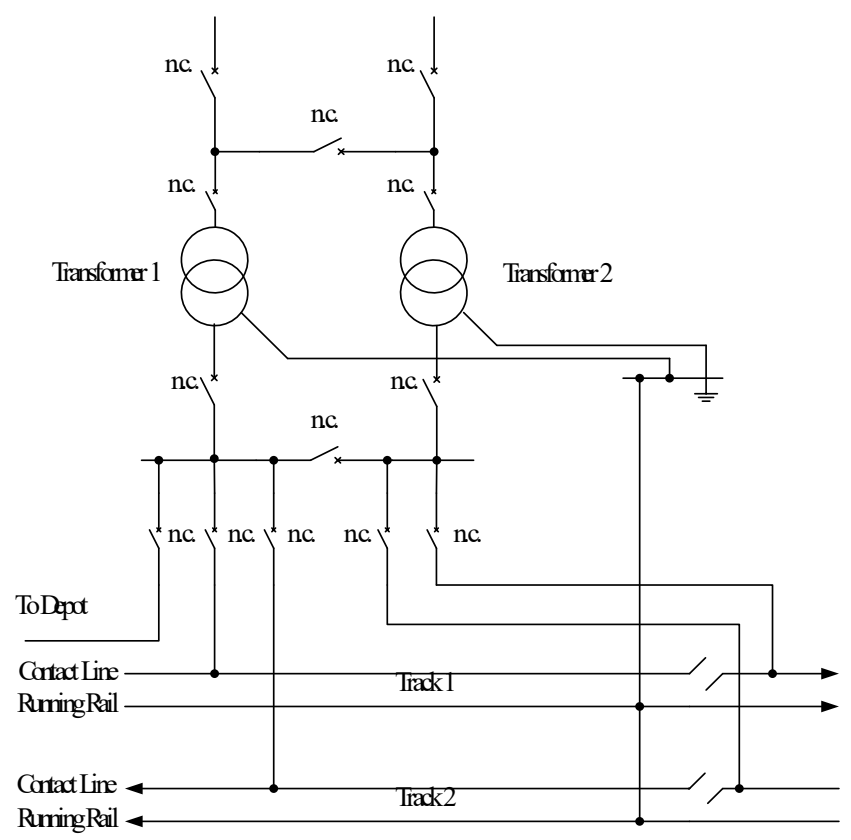

Figure 5. The substation infeed with two transformers [1].

\subsection{Overhead Contact System}

The overhead contact system in Figure 6 consists of catenary (C), rails (R), and earth (E) described as follows: the catenary (C) is formed by a contact wire and one or two messenger wires. They share the current and are always at the same potential. To reduce the system complexity, their impedances are combined all together to form a single conductor. There are two rails (R) in the same track, which are treated as a single cylindrical conductor. There is a wire called "earth wire" that is used for safety reasons and it normally carries no current. It is assumed that the leakage current from the rails flows underneath the track with a depth of $\mathrm{D}_{\mathrm{E}}$ through a virtual conductor called the return earth by (7) and an earth resistivity can be calculated by (8):

$$
\begin{aligned}
& \mathrm{D}_{\mathrm{E}}=655 \sqrt{\frac{\rho_{E}}{\mathrm{f}}} \\
& \rho_{E}=547 \mathrm{f}^{-0.434}
\end{aligned}
$$

where $\mathrm{f}$ is an operating frequency $(\mathrm{Hz})$ and $\rho_{E}$ is the earth resistivity $(\Omega \cdot \mathrm{m})$.

A reactance caused by electrical induction play an important role in a transmission system for an AC railway power supply. The value of conductor's reactance in the system is dependent on the conductor arrangement and the distance between conductors, see Figure 6. Impedance per unit length of the catenary and running rail is expressed in (9) and (10).[9]: 


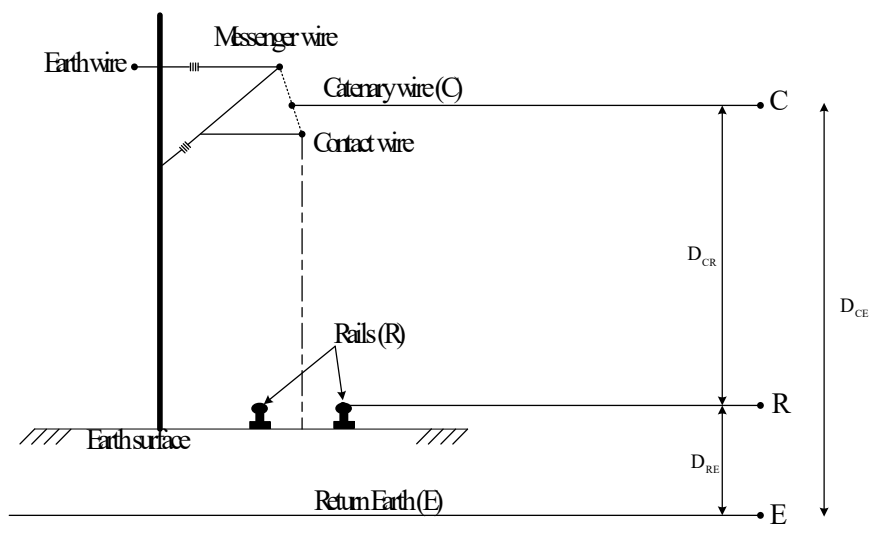

Figure 6. Overhead contact system configuration 「91.

$$
\begin{gathered}
Z_{C}=R_{C}^{\prime}+j 2 \pi f \mu_{0}\left(\frac{1}{8 \pi}+\frac{1}{2 \pi} \ln \frac{D_{C E}}{G M R_{C}}\right) \\
Z_{R}=R_{R}^{\prime}+j 2 \pi f \mu_{0}\left(\frac{\mu_{R}}{8 \pi}+\frac{1}{\pi} \ln \frac{D_{R E}^{2}}{R G \times G M R_{R}}\right)
\end{gathered}
$$

where

$Z_{C}$ is catenary's impedance per unit length $(\Omega / \mathrm{km})$

$Z_{R}$ is rail's impedance per unit length $(\Omega / \mathrm{km})$

$R_{C}^{\prime}$ is catenary's resistance per unit length

$R_{R}^{\prime}$ is rail's resistance per unit length

$\mu_{0}$ is magnetic permeability of air

$\mu_{R}$ is magnetic permeability of rails

$G M R_{C}$ is catenary's geometric mean radius

$G M R_{R}$ is rail's geometric mean radius

$R G$ is a distance between rails in the same track

$D_{C E}$ is a distance between catenary and earth

$D_{R E}$ is a distance between rail and earth

\section{Modelling and Simulation Procedure}

The model of the traction transformer, catenary, rails and train of the ARL are modelled by using the built-in blocks in MATLAB/SIMULINK. The configuration of the ARL power supply system is briefly mentioned. Lastly, the evaluation of the VUF at the traction substation of the ARL with different scenarios of the train operations is discussed as follows:

\subsection{The model of the transformer in the traction substation}

The two traction transformers in the ARL traction substation are alternately connected to different pairs of phases. To estimate the operational voltage and voltage unbalance at the traction substation, the transformer model is formed by using the multi- winding transformer built-in block in MATLAB/SIMULINK program described as follows:

This connection has the same configuration as the single-phase connection except it connects to different pairs of phases. For example, the first transformer is connected to phase $\mathrm{AB}$ and the second transformer is connected to phase $\mathrm{BC}$ as shown in Figure 7.

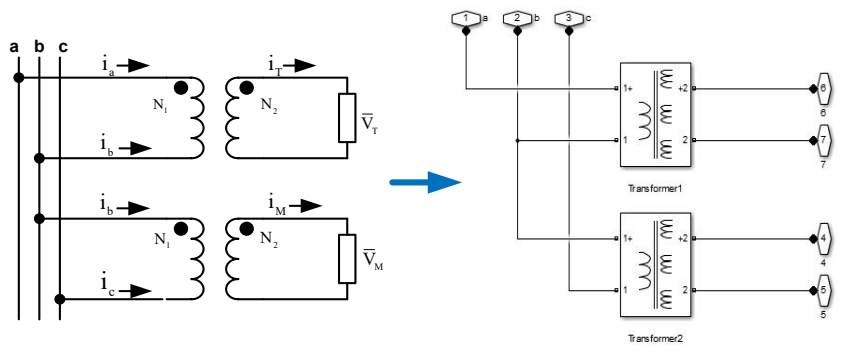

Figure 7. Cyclic permutation of phase connection in MATLAB/SIMULINK.

\subsection{ARL traction power supply modelling in MATLAB/ SIMULINK}

The AC traction power supply modelling is developed in the block models in MATLAB/SIMULINK. The model consists of 4 main parts: (i) $\mathrm{AC}$ traction substation, (ii) transformers, (iii) overhead catenary system, and (iv) electric trains as shown in Figure 8. The $69 \mathrm{kV}$ three-phase $\mathrm{AC}$ transmission system is represented by the three-phase source built-in block. The transformers will step down the voltage from $69 \mathrm{kV}$ to $27.5 \mathrm{kV}$ using the multi-winding built-in block connected as a cyclic permutation of phases. The overhead catenary and running rails have the impedances obtained from the textbook [9] and BS EN 50149:2012 standard. The series RLC branch built-in block is used to model this transmission and return circuit system. Lastly, the electric trains are modelled as a series RLC load.

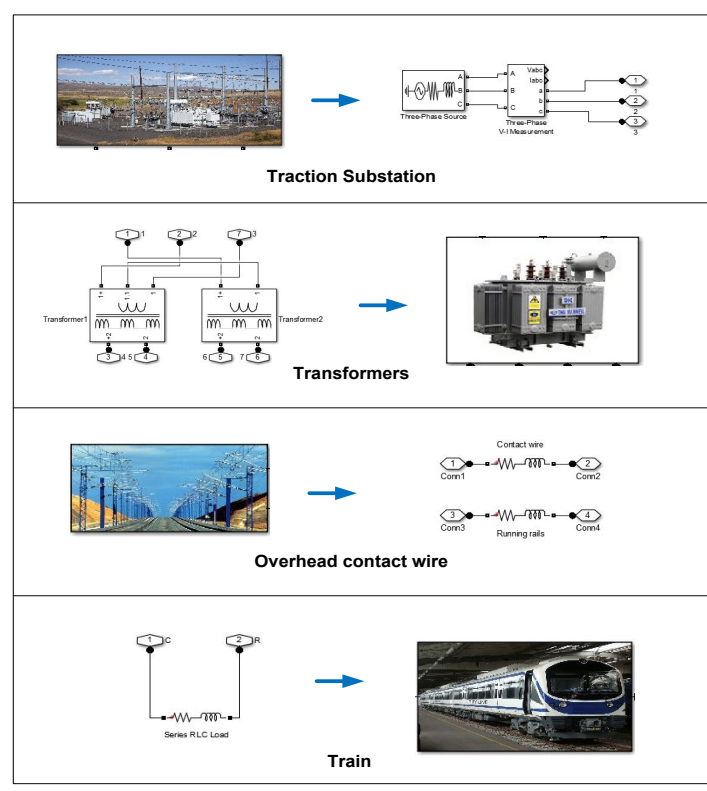

Figure 8. The power feeding components' models in MATLAB/SIMULINK. 
The ARL system was modelled for the simulation tests in this paper. The ARL was the first electric mass transit railway operated with overhead catenary system or overhead contact system to commence operations in Thailand. The ARL is composed of 8 passenger stations and one traction substation as shown in Figure 9. Parameters' setting for this simulation can be found in Appendix.

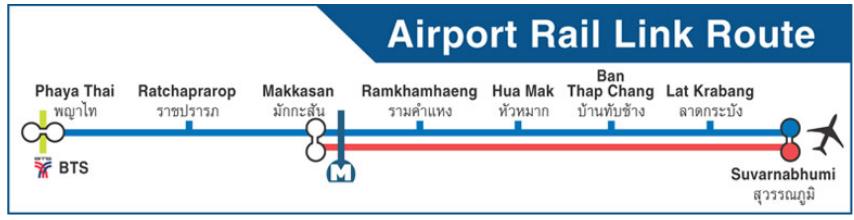

Figure 9. Suvarnabhumi Airport Rail Link map 「1].

The AC traction substation of the ARL draws the electrical energy with the voltage level of $69 \mathrm{kV}$ from the metropolitan electricity authority (MEA). The traction substation transformers with an alternate phase connection transform the grid voltage into the train's nominal voltage of $27.5 \mathrm{kV}$. The total service distance is $28.298 \mathrm{~km}$ and the traction substation's position is at $8.078 \mathrm{~km}$. In the simulation, the trains depart from both tracks at the same time with the same headway throughout the service, e.g. the first and fifth trains start the operation at the same time, also the second and the sixth trains and so on as shown in Figure 10.

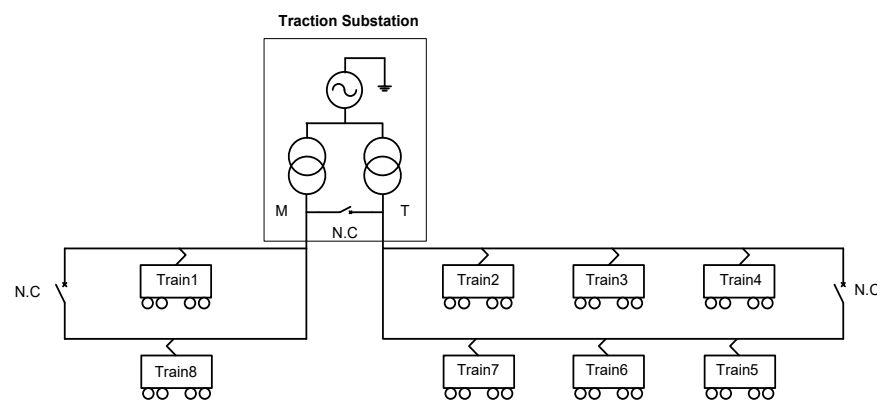

Figure 10 . The schematic diagram of the ARL traction power supply system [1].

\subsection{Simulator structure}

The simulator has 2 major parts: main program (script M-file) and the power network solver (SIMULINK). The main program performs the multi-train movement, performance calculation, and the network capture, i.e. sorting trains on service, setting the distances between the components in the system and the train data. Then, the trains' positions and powers together with the distances recently mentioned are transferred into the SIMULINK block model to solve the voltage solution (primary and secondary voltages of the substation) and VUF. Finally, those values are returned to the main program to be stored and display the graphical illustration. The operating diagram is shown in Figure 11.

\section{Simulation Results and Discussion}

The results showed the VUFs at the point of common coupling of the ARL traction substation with four different scenarios as shown in Figure 12. The operational conditions, i.e. headways and the train configurations, are given in Table 1. Each train has the maximum speed of $70 \mathrm{~km} / \mathrm{h}$ and the speed profile is shown in Figure 13.

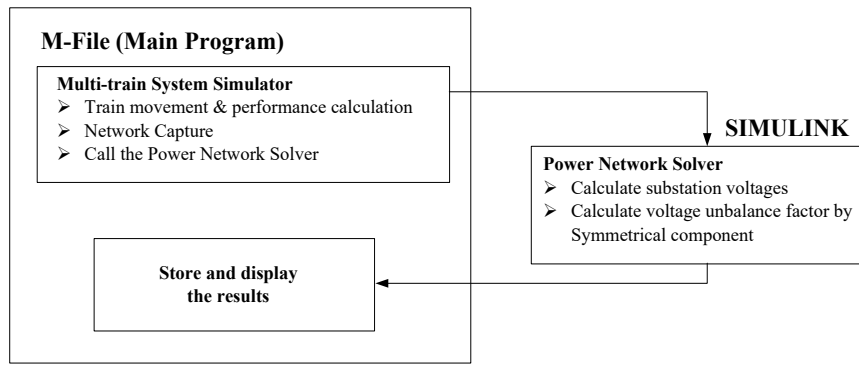

Figure 11. Diagram of the simulation program.

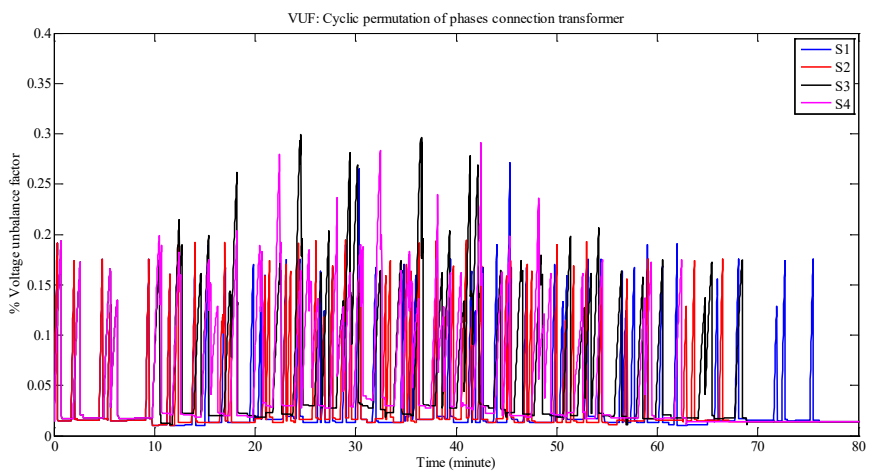

Figure 12. Percentage of VUFs in each scenario

Table 1: Operational conditions of Suvarnabhumi Airport Rail Link.

\begin{tabular}{|c|c|c|c|c|}
\hline Scenario & Headway & $\begin{array}{c}\text { Train } \\
\text { configuration }\end{array}$ & $\begin{array}{c}\text { Total } \\
\text { weight }\end{array}$ & $\begin{array}{c}\text { Auxiliary } \\
\text { power }\end{array}$ \\
\hline S1 & $15 \mathrm{~min}$ & 3 car train & $183.67 \mathrm{t}$ & $200 \mathrm{kVA}$ \\
\hline S2 & $12 \mathrm{~min}$ & 3 car train & $183.67 \mathrm{t}$ & $200 \mathrm{kVA}$ \\
\hline S3 & $12 \mathrm{~min}$ & $4+3$ car train & $422.64 \mathrm{t}$ & $450 \mathrm{kVA}$ \\
\hline S4 & $10 \mathrm{~min}$ & $4+3$ car train & $422.64 \mathrm{t}$ & $450 \mathrm{kVA}$ \\
\hline
\end{tabular}

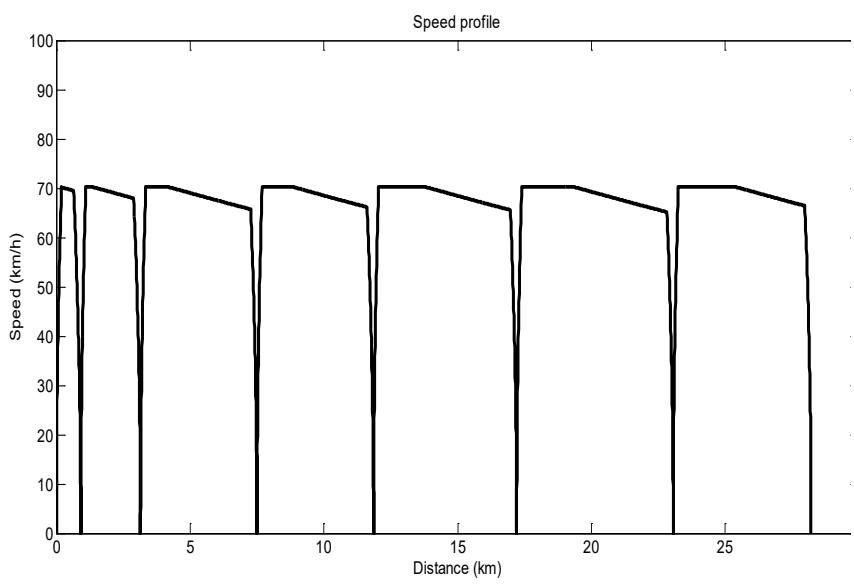

Figure 13. Speed profile.

Considering scenario S1 and S2 in Figure 12, the VUF obtained from S2 was found to be lower than that from S1 because the total weight and auxiliary power of S1 and S2 are equal to each other but the headway of S1 is longer than that of S2. It can be noted that when the headway is shorter, the number of trains appear 
in the system, so the total loads on the left and the right of the substation were more likely to have the same values leading to less voltage unbalance. To study the effect of different total weight and auxiliary power of the train on the voltage unbalance, scenario S2 and S3 were compared. As the total weight and auxiliary power load of S3 were greater than those of S2, more power would be consumed in S3, and there was more possibility of different amount of consumed power between the left and right side of the traction substation. Thus, the voltage unbalance of S3 was more than that of S2. In addition, the comparison between S3 and S4 gave the same result as the S1-S2 comparative result. However, due to more weight and auxiliary power load in S3 and S4 compared to S1 and S2, the voltage unbalance in S3 and S4 was more than that of S1 and S2, respectively and the voltage unbalance of S3 was more than that of S4 because the headway of $\mathrm{S} 3$ was longer. In the viewpoint of the maximum \%VUF for each scenario as shown in Table 2, it helped confirm the above explanation since the results seen from Figure 12 were consistent with the results from Table 2 .

From the results, it could be concluded that the longer the headway, the more voltage unbalance. That meant the voltage unbalance was more reduced when the trains were released more frequently. The total weight and auxiliary power also affected the voltage unbalance. According to IEEE $1159-2009$ standard, the $\%$ VUF must not exceed $2 \%$. Therefore, the service extension of the ARL can be carried out without any violation of voltage unbalance based on this simulation results.

Table 2: The Maximum \%VUF

\begin{tabular}{ccc}
\hline \hline Scenario & \%VUF Max & $\begin{array}{c}\text { Comparison with IEEE 1159 -2009 } \\
\text { standard (2\%) }\end{array}$ \\
\hline S1 & 0.2717 & Less than 2\% (passed) \\
S2 & 0.1946 & Less than 2\% (passed) \\
S3 & 0.2993 & Less than 2\% (passed) \\
S4 & 0.2906 & Less than 2\% (passed) \\
\hline
\end{tabular}

\section{Conclusion}

This paper presents the study of voltage unbalance caused by the AC railway power supply system using MATLAB/Simulink . The VUF was the key factor in this consideration. The test system was the ARL linking Suvarnabhumi airport to the Bangkok city center .The traction transformer connection type was the cyclic permutation of phases .The VUF was estimated in four scenarios of the train operations. The results showed that at the same headway, the VUF was increased when the train weight and auxiliary power load were increased due to the increase in energy drawn by the trains .For different headways, the longer the headway, the more voltage unbalance. However, the increased VUF was still within the limit of $2 \%$ imposed by IEEE $1159-$ 2009 in every scenario .Accordingly, the extension plan of the ARL by increasing routes, service distance, and the number of trains in the future will slightly affect the voltage unbalance. However the VUF is limited within the acceptable value.

\section{Acknowledgment}

We would like to express our sincere gratitude to Suranaree University of Technology for financially supporting this research.

\section{Appendix}

Overhead catenary system for ARL:

- Contact wire: $\mathrm{Cu} 107 \mathrm{~mm}^{2}$ (20\% abrasion)

- Messenger wire: $\mathrm{Bz} 70 \mathrm{~mm}^{2}$

- Return Conductor: E-Al 120 $\mathrm{mm}^{2}$

- Rails: UIC $60,15 \%$

Traction power substation for ARL:

- 2x20 MVA transformers (cyclic connection)

- $69 / 27.5 \mathrm{kV}, 12 \%$ impedance, ONAN

- Short-circuit power of the substation is $2.7 \mathrm{GVA}$

Train resistance parameters:

\begin{tabular}{|l|l|}
\hline 3-car train & 4+3-car train \\
\hline Tare weight: 131 tons & Tare weight: 299 tons \\
\hline Rotary portion of tare weight: $6 \%$ & Rotary portion of tare weight: $6 \%$ \\
\hline Maximum payload: 44.9 tons & Maximum payload: 105.7 tons \\
\hline Maximum design speed: $160 \mathrm{~km} / \mathrm{h}$ & Maximum design speed: $160 \mathrm{~km} / \mathrm{h}$ \\
\hline Maximum acceleration: $1 \mathrm{~m} / \mathrm{s} 2$ & Maximum acceleration: $1 \mathrm{~m} / \mathrm{s} 2$ \\
\hline Maximum deceleration: $0.88 \mathrm{~m} / \mathrm{s} 2$ & Maximum deceleration: $0.88 \mathrm{~m} / \mathrm{s} 2$ \\
\hline Gear/Motor/converter efficiency: $82 \%$ & Gear/Motor/converter efficiency: $82 \%$ \\
\hline Maximum auxiliary power: $200 \mathrm{kVA}$ & Maximum auxiliary power: $450 \mathrm{kVA}$ \\
\hline Maximum tractive effort: $200 \mathrm{kN}$ & Maximum tractive effort: $400 \mathrm{kN}$ \\
\hline Train resistance formula: & Train resistance formula: \\
$\mathrm{A}=2.1222$ & $\mathrm{~A}=4.8438$ \\
$\mathrm{~B}=0.00618$ & $\mathrm{~B}=0.01412$ \\
$\mathrm{C}=0.3197$ & $\mathrm{C}=0.53287$ \\
\hline
\end{tabular}

\section{References}

[1] N. Mingpruk, U. Leetonand, T. Kulworawanichpong, "Modeling and simulation of voltage unbalance in $\mathrm{AC}$ electric railway systems using MATLAB/Simulink". IEEE/SICE International Symposium on System Integration, 2016.

[2] Applications of Mathematics, "Tractive effort, acceleration and braking", The Mathematical Association, 2004.

[3] S. Lu, "Optimising power management strategies for railway traction". $\mathrm{PhD}$ Thesis, University of Birmingham, UK, October 2011.

[4] BP. Rochard, F. Schmid, "A review of methods to measure and calculate train resistances". Proceedings of the Institution of Mechanical Engineers, Part F: Journal of Rail and Rapid Transit, Vol. 214, No. 4, p. 185-199, 2000.

[5] T. Kulworawanichpong, "Optimising AC electric railway power flows with power electronic control". PhD Thesis, University of Birmingham, UK, November 2003.

[6] M. Kalantari, M. J. Sadeghi, S. Farshad, S. S. Fazel, "Modeling and Comparison of Traction Transformers Based on the Utilization Factor Definitions", Internation Review on Modelling and Simulation (I.RE.MO.S.), Vol. 4, N. 1, pp. 342 - 351, February 2011.

[7] IEEE recommended practice for monitoring electric power quality, IEEE std 1159 - 2009 (Revision of IEEE std 1159 - 1995), pp. c1 - 81, June 2009

[8] F. Ciccarelli, M, Fantauzzi, D. Lauria, R. Rizzo, "Special Transformers Arrangement for AC Railway Systems," Department of Electrical Engineering - University of Naples Federico II, Naples (Italy), 2014.

[9] F. Kiessling, R. Puschmann, A. Schmieder, E. Schneider, Contact Lines for Electric Railways, 2nd revised and enlarged edition, pp. $664-666,2009$. 